\title{
Espaço Público em Sítios Históricos Urbanos no Processo de Formação Territorial na América Latina ${ }^{1}$
}

\author{
Espacio Público en Sitios Historicos Urbanos en el Proceso de Formación \\ Territorial en América Latina
}

\author{
Public Spaces in Historical Urban Sites in the Process of Territorial \\ Formation in Latin America
}

\author{
Rosalina Burgos ${ }^{2}$
}

\begin{abstract}
Resumo
O processo de formação territorial dos países latino-americanos envolve a gênese dos primeiros núcleos urbanos, num percurso de transformações socioespaciais e consolidação de um conjunto de sítios históricos urbanos na contemporaneidade. Apresentam-se como lócus para estudos sobre memória, identidade e patrimônio para diversas áreas do conhecimento. A partir da questão sobre a gênese, transformação e devir do espaço público, analisou-se o caso da cidade de Iguape no litoral sul paulista, região do Vale do Ribeira que possui territórios indígenas e quilombolas. Para um estudo comparativo no contexto do cone sul latino-americano, analisou-se a cidade de Colônia do Sacramento (Uruguai) bem como o território de fronteira das missões jesuíticas guaranis entre Brasil, Paraguai e Argentina. Caracterizam-se pela gênese num contexto de disputas territoriais no período colonial e por se constituírem na atualidade como patrimônios históricos, revelando ainda hoje conflitos na apropriação de seus espaços públicos em diferentes níveis que incidem sobre o cotidiano. Neste processo, a noção de espaço público subjaz à racionalidade eurocêntrica presente na concepção dos planos urbanísticos e nos padrões de sociabilidade impostos. Há, neste sentido, um hiato que separa uma concepção hegemônica de ver e compreender o mundo em detrimento daquelas que sucumbiram sob a força da violência no decurso da colonização portuguesa e espanhola. Entende-se que os espaços públicos abrigam uma densidade histórica que expressa a sobreposição de conflitos nos diferentes períodos da formação territorial desde o período colonial, apresentando-se como importante campo de investigação para compreensão do devir.
\end{abstract}

Palavras-Chave: cotidiano; espaço público; fronteira; patrimônio histórico; sítio histórico urbano

\section{Resumen}

El proceso de formación territorial de los países latinoamericanos involucra la génesis de los primeros núcleos urbanos, en un recorrido de transformaciones socioespaciales y consolidación de un conjunto de sitios históricos urbanos en la contemporaneidad. Se presentan como lócus para estudios sobre memoria, identidad y patrimonio para diversas áreas del conocimiento. A partir de la cuestión sobre la génesis, transformación y devenir del espacio público, se analizó el caso de la ciudad de Iguape en el litoral sur paulista, región del Valle del Ribeira que tiene territorios indígenas y quilombolas. Para un estudio comparativo en el contexto del cono sur latinoamericano, se analisó la ciudad de Colonia del Sacramento (Uruguay) así como el territorio de frontera de las misiones jesuíticas guaraníes entre Brasil, Paraguay y Argentina. Se caracterizan por la génesis en un

\footnotetext{
${ }^{1}$ Artigo apresentado no Simpósio Temático Repensar, Refletir, Interpretar e Reinterpretar a memória, identidade e o patrimônio cultural da América Latina durante o II Seminário Latino-Americano de Estudos em Cultura SEMLACult em Foz do Iguaçu/PR, Brasil, 2018.

2 Doutora em Geografia Humana (USP); Docente do Departamento de Geografia, Turismo e Humanidades DGTH - UFSCar; Sorocaba, São Paulo, Brasil; rburgos.ufscar@gmail.com
} 
contexto de disputas territoriales en el período colonial y por constituirse en la actualidad como patrimonios históricos, revelando aún hoy conflictos de apropiación de sus espacios públicos en diferentes niveles que inciden sobre lo cotidiano. En este proceso, la noción de espacio público subyace a la racionalidad eurocéntrica presente en la concepción de los planes urbanísticos y en los patrones de sociabilidad impuestos. Hay, en este sentido, una brecha que separa a una concepción hegemónica de ver y entender el mundo a expensas de los que han sucumbido bajo la fuerza de la violencia durante la colonización portuguesa y española. Se entiende que los espacios públicos albergan una densidad histórica que expresa la superposición de conflictos en los diferentes períodos de la formación territorial desde el período colonial, presentándose como un importante campo de investigación para la comprensión del devenir.

Palabras claves: espacio público; frontera; patrimonio historico; sitio historico urbano; vida cotidiana

\begin{abstract}
The process in territorial transformation of the Latin-American countries involves the first urban cores, along a course of socio-spatial transformation and consolidation of a group of historical urban sites in contemporaneity. It is presented as a lócus for studies about memory, identity and patrimony for several fields of knowledge. Starting from the point of genesis, transformation and changes in public space, it was analyzed Iguape city case, in the south coast of São Paulo state, Vale do Ribeira region which gathers indian territories and maroon communities. As a comparison in the southern continent context in Latin America, It was considered the Uruguayan city Colônia do Sacramento as well as the frontier territory for Jesuit Guarani missions among Brazil, Paraguay and Argentina. It is characterized by the genesis in a context of land disputes in the colonial period and by constituting in the present days as historical patrimonies, having revealed even today conflicts of appropriation in its public spaces in different levels that interfere on everyday life. During this process, the idea of public space underlies the eurocentric rationality in the current conception of urbanistic planning and the sociability patterns imposed by it. There is a gap that puts a hegemonic conception apart from seeing and comprehending the world to the detriment of those who collapsed by the force of violence in the course of Portuguese and Spanish colonization. It is understandable that public spaces gathers a historical density, which expresses the conflict overlap in different periods of territorial development since colonial ages, being presented as an important field of investigation to comprehend the changes.
\end{abstract}

Keywords: everyday life; frontier; historical patrimony; historical urban sites; public spaces

\title{
1. Introdução
}

Parte-se da análise do processo de gênese, transformação e devir de espaços públicos em determinados sítios históricos no contexto latino-americano. A ênfase do estudo está na análise de espaços públicos que integram o perímetro de dois centros históricos urbanos e de um território de fronteira no qual se encontram sítios arqueológicos com origens no período colonial. Em todos os casos analisados, observou-se os seguintes atributos: a) gênese no período colonial, detendo importância histórica para a compreensão do processo de formação territorial latino-americano; b) situação geográfica na faixa litorânea e/ou às margens de rios com significativa importância para o processo de ocupação territorial, incluindo a função portuária e/ou de defesa territorial; c) situação geográfica com menor impacto dos processos recentes de urbanização e metropolização (que tendem a descaracterizar demasiadamente os vestígios e resíduos espaciais pretéritos), e com presença de intervenções de políticas de 
espaço ligadas às leis relativas ao patrimônio histórico e urbanístico; d) relevância arquitetônico-paisagística referente ao tema do patrimônio e de interesse turístico.

Para tanto, objetivou-se analisar e compreender a relação existente entre as formas de concepção, uso e apropriação de espaços públicos de duas cidades fundadas no período colonial (e sobre as quais hoje incidem leis do patrimônio e interesses turísticos), e ainda o território de fronteira que reúne sítios arqueológicos das missões jesuíticas guaranis, enquanto caminho investigativo acerca dos conteúdos dos conflitos socioespaciais e da sociabilidade na constituição da esfera público-política. As áreas de estudo são: Iguape (cidade localizada no litoral sul do Estado de São Paulo/Brasil, no complexo estuarino-lagunar de Cananéia-Iguape) definida como principal área de estudo; Colônia do Sacramento (localizada na margem oriental do Rio da Prata ou Mar del Plata, no Uruguai) e o território que integra um conjunto de sítios arqueológicos das antigas missões jesuíticas guaranis na fronteira entre Brasil, Paraguai e Argentina, definido como área de estudo complementar para análise comparativa e mais abrangente em termos dos processos históricos identificados no contexto latinoamericano, mais especificamente do denominado cone sul. Essas áreas de estudo estiveram diretamente envolvidas nos processos de definição das fronteiras territoriais das então colônias das coroas ibéricas (Portugal e Espanha).

Em termos metodológicos, observou-se as seguintes etapas de trabalho: pesquisa bibliográfica, documental, iconográfica e cartográfica (em acervos de referência sobre a temática abordada) relacionadas ao processo de formação, transformação, uso e apropriação pretéritos e contemporâneos dos espaços públicos das áreas analisadas; trabalhos de campo para observação e análise das formas de sociabilidade, conflitos socioespaciais, aspectos de resistência e resíduos que expressam conteúdos de práticas espaciais pretéritas e daquelas que se perpetuam no espaço público hodierno; sistematização e exposição dos resultados.

Por fim, tendo como base esse contexto, ressalta-se que as áreas de estudo embora não sejam contíguas territorialmente, apresentam-se como panorama para estudos sobre a gênese, transformação e devir dos espaços públicos, estando articuladas no processo de formação territorial no cone sul latino-americano.

\section{Iguape, Colônia do Sacramento e missões jesuíticas guarani: territórios em disputa no processo de formação territorial no cone-sul latino-americano}

O processo de formação territorial dos países latino-americanos envolve a gênese dos primeiros núcleos urbanos, num longo percurso de transformações socioespaciais e 
consolidação de um conjunto de sítios históricos na contemporaneidade. Um recuo no tempo histórico de longa duração, localiza-se a gênese desse processo para além do período colonial, ou seja, na pré-história propriamente dita, considerando as formas de uso e apropriação do espaço pelos povos indígenas que já faziam dessas terras seus territórios de vida. Sob essa perspectiva se situa a análise sobre o território das missões jesuíticas guarani. No outro extremo do processo, o devir ainda guarda a possibilidade de realização dos sentidos do espaço público, que no decurso de sua gênese e transformação expõe os conflitos de uma sociedade que reproduz e aprofunda os fundamentos da desigualdade.

Os sítios históricos, seja no caso das cidades de Iguape e de Colônia do Sacramento, seja no caso das ruínas das missões jesuíticas guaranis, são formados no período colonial e se apresentam como base para a análise da gênese e das metamorfoses do espaço público. Suas respectivas origens estão situadas no contexto do sistema mercantil sob comando das metrópoles europeias, no qual se encontra grande parte das fontes documentais sobre a temática naquele período. Contudo, observa-se que nessas fontes documentais produzidas no período colonial, a presença indígena não recebe destaque enquanto protagonista da produção do espaço; quando muito os indígenas são apresentados como coadjuvantes subjugados. Há que se considerar a participação direta que tiveram na organização do trabalho - ainda que sob expropriação - e consequentemente da formação territorial, no decurso da qual tiveram seus territórios arrasados e subtraídos (cabe nessa perspectiva o termo redução usado genericamente como sinônimo de missão jesuítica), cujos contingentes populacionais conheceram verdadeiro genocídio, inúmeras vezes denunciado por pesquisadores latinoamericanos na contemporaneidade.

Ressalta-se que as disputas territoriais entre as coroas ibéricas articulam num mesmo contexto as três áreas de estudo: Iguape, Colônia do Sacramento e o território das missões jesuíticas guaranis, também denominado como território missioneiro.

A cidade de Iguape foi elegida como principal área desse estudo. Está localizada na porção sul do território paulista, distante cerca de $200 \mathrm{~km}$ da metrópole de São Paulo, e apresenta uma população urbana em torno de 25.000 habitantes. Encontra-se no contexto regional do Vale do Ribeira (baixo rio Ribeira de Iguape) o qual apresenta um panorama problemático em termos socioeconômicos, mas com rica diversidade ambiental e cultural:

A região do Vale do Ribeira e do litoral é de grande diversidade cultural, nela encontrando-se povos indígenas como os Guaranis, os caiçaras, descendentes dos índios, sobretudo dos Carijós, colonizadores portugueses e escravos negros, caipiras, no Alto e Médio Ribeira, além de inúmeros núcleos quilombolas, remanescentes da mão-de-obra escrava usada nas monoculturas e na mineração e de caipiras, 
existentes, sobretudo no Médio e Alto Ribeira. A esses grupos humanos vieram se ajuntar, mais tarde, outros migrantes europeus como suíços, franceses, alemães, italianos, também norte-americanos e japoneses. (DIEGUES, 2007, p.4)

Nesse contexto, o Vale do Ribeira possui núcleos de ocupação que datam dos primórdios da formação territorial, dentre os quais se destaca a cidade de Iguape:

A sua arquitetura e urbanismo remontam ao período da exploração aurífera e às conquistas do território no século XVI, às atividades ligadas à construção naval no século XVIII e à cultura de arroz no século XIX, as quais estruturadas por trama urbana singular, resultam em núcleo urbano notável no contexto das cidades da América Portuguesa. (NASCIMENTO; SCIFONI, 2015, p.27)

Do seu traçado original, o centro histórico de Iguape herdou um conjunto de espaços públicos que oferece substrato e conteúdos socioespaciais da formação social, sinalizando um território propício às análises da gênese, transformação e devir em relação às formas de concepção e uso.

O processo de formação desta cidade carrega uma valorosa história territorial que muito revela sobre nosso passado colonial e pré-histórico, e que abrange extensão mais ampla do que o perímetro tombado.

Estudiosos da região do Vale do Ribeira, com base em informações de caráter arqueológico observam que os núcleos coloniais de Cananéia e Iguape, considerados dentre os mais antigos, foram transferidos dos locais onde originalmente foram fundados: do vilarejo de Icapara para o atual centro de Iguape e do vilarejo de Maratayama para o atual centro de Cananéia. Justificativas envolvem aspectos ligados à proteção (sobretudo ataques marítimos) mas também se aponta a necessidade de condições espaciais para sua maior expansão a partir do modelo fundador de uma igreja matriz e praça (praça da matriz).

Comprovada por prospecções arqueológicas, os respectivos núcleos foram fundados sobre antigos locais de ocupação indígena de nossa pré-história. Ou seja, há nestes territórios camadas de tempo e espaço que embora encobertos pelas novas ocupações situam a gênese do processo de formação territorial em contextos pretéritos ao período colonial.

Se para o caso dos territórios andinos onde se localizam as ruínas de antigas civilizações (com destaque para Peru, Bolívia e México) a concretude e magnitude dos sítios arqueológicos são evidentes na paisagem (a exemplo de Machu Picchu e outros), o contexto analisado apresenta vestígios muito mais sutis, o que dificulta a análise, mas não a impossibilita. Daí a importância, já anunciada, do diálogo entre a geografia e a arqueologia. No baixo curso do Rio Ribeira, por exemplo: 
(...) os sítios localizam-se em pequenas elevações na margem do Ribeira e junto aos seus principais afluentes da margem direita, Jacupiranga, Pariqueraçú e Momuna (...): Ao longo do mar Pequeno, entre Iguape e Icapara, em uma faixa de $12 \mathrm{Km}$ em linha reta, pudemos evidenciar três sítios, sendo que esta região à beira mar os sítios são mais próximos do que subindo o Ribeira, Resumindo, os sítios evidenciados até agora são sítios-habitações (...). Apresentam grande quantidade de cerâmica e nos dois sítios mais próximos ao mar Pequeno, que foram escavados, foram encontrados material de contato, como contas de vidro e pedaços de ferro. (SCATAMACCHIA, 1990, p. 204).

É neste contexto que reúne um mosaico singular de paisagens e conteúdos históricoculturais que o sítio urbano de Iguape se insere. Se a gênese do seu processo de formação é demarcada pela historiografia no período colonial, importa ressaltar que seu território possui registros de ocupação efetiva do território desde a pré-história, a exemplo dos sambaquis que pontilham sua extensão territorial e aldeias indígenas.

Numa suave colina delineada pelo Mar Pequeno e o Córrego Lavapés (e posteriormente também pelo Valo Grande) se espraia a cidade de Iguape. Roberto Fortes descreve com beleza de detalhes a malha viária em simbiose com as formas do relevo, que em conjunto vai articulando largos e praças amalgamadas pelo arruamento. Gianesella (2008: 141-142) mais uma vez nos brinda com impecável descrição:

(...) Ressalvadas a adequação ambiental das linhas do 'funil', imposição limítrofe do sítio no altiplano conformado pelo Córrego Lavapés, afluente do Mar Pequeno, os alinhamentos da praça parecem adequados à perpendicular da 'rua direita', diretriz do porto fluvial do Rio Ribeira, indicada a Noroeste. Sabemos que a instalação da matriz na vila, com as obras iniciadas em 1614, foi uma das primeiras providências dos colonos para a mudança da sede, que ocupava o povoado de Icapara. A historiografia informa também que as primeiras casas foram 'arruadas' no alinhamento paralelo ao porto marítimo do Mar Pequeno (FORTES, 2000, p.169), coerente com o talude das bordas do altiplano, portanto um traço ambientado à topografia e adequado à ortogonalidade da futura 'rua direita'. A localização sugere uma premência descompromissada com as subsequentes edificações do núcleo.

Não se trata exclusivamente de uma concepção eurocêntrica para escolha desse padrão de sítio a ser ocupado, mas um conhecimento já delineado pelos povos indígenas que os europeus aqui encontraram. Gianesella $(2008$, p.140) assim indica: "é quase certo que a própria cidade de Iguape esteja situada sobre uma antiga aldeia indígena, pois em várias ruas do perímetro urbano foram identificados vestígios cerâmicos, tendo a SABESP, há (...) anos atrás, executando trabalhos de saneamento, encontrado urnas (indígenas) no largo da matriz". 
Em termos da cultura que resulta e se expressa na atualidade, adentrando espaços públicos por ocasião de festejos populares e eventos culturais promovidos, destaca-se as influências da presença da população negra em Iguape, nas manifestações culturais como a Marujada, o Congo ou Congada, o Jongo e o Vilão. Sobre a Marujada, Fortes (2000, p.135) observa sua adaptação regional da tradição lusa, rememorando o episódio da Guerra de Iguape, travada com São Vicente entre portugueses e espanhóis, em 1534. Sobre o conjunto arquitetônico, Fortes (2000, p.163) também recorre às contribuições de YOUNG (1902), do qual se tem a informação sobre as edificações mais antigas da cidade, o que indica uma qualidade peculiar a ser destacada para o conjunto arquitetônico tombado: trata-se de edificações simplórias, casas térreas e geminadas, de pequena extensão de acordo com o modelo "porta e janela" defronte à calçada, sugerindo que desde tempos remotos a função de moradia popular esteve presente no perímetro que hoje é tombado. Por outro lado, os casarões ainda existentes e tombados em seu centro histórico denotam a riqueza acumulada nos ciclos do ouro e do arroz naquela região. No período compreendido pela antiga Província de São Paulo, a cidade de Iguape ocupou lugar de destaque. As atividades culturais existentes (abrigadas em alguns dos casarões que permanecem na paisagem urbana da cidade) nos dão uma mostra disso: clubes, teatros, hotéis, jornais, ópera, escolas de idiomas, lojas de artigos especializados, dentre outros. Notável destaque recai sobre o Porto Grande, com movimentação de navios de diversas origens no país e do exterior. Fortes (2000, p. 173-174) em mais uma de suas contribuições com base na análise documental indica a magnitude deste período: é curioso observar que, no período de 1836 a 1854, Iguape chegou a possuir mais habitantes que Santos. Em 1836, Iguape possuía 9396 habitantes, contra 5863 de Santos. Em 1854, contava com 15211 habitantes; Santos com 7033.

Mas, já no século seguinte, Iguape se insere num longo período de decadência, o que aponta para a correspondência entre o advento da mão de obra livre como o grande impacto na economia, que viria a ser ainda mais atingida com o comprometimento da função portuária, decorrente dos impactos advindos da abertura do Valo Grande e posterior assoreamento do Mar Pequeno, situação que ainda pesa sobre o cotidiano dos dias atuais.

Se o ouro definiu os marcos da Lei e dos primórdios da gestão pública de Iguape, o arroz fez florescer a elite local, do que resulta as referências acerca das atividades culturais por ela desempenhadas. Define-se uma sociedade elitista e patriarcal constituída por famílias que se destacam nas artes, música, letras e política, cujos nomes povoam a cidade até hoje. Esta sociedade escravocrata está nas origens da definição original dos espaços públicos e do domínio do privado, a exemplo dos casarões que demarcam o acúmulo de riqueza. Indígenas 
e negros africanos, embora não convidados a participar das manifestações culturais, ainda assim se perpetuaram na cidade e região. Por ocupar lugar periférico no dinamismo socioeconômico e das transformações socioculturais do intenso processo de industrializaçãourbanização do território paulista, Iguape seguiu lentamente resguardando culturas ancestrais, tendo chegado no século XXI detendo uma pluralidade cultural étnica significativa. Disso decorre a compreensão de que em Iguape o devir ainda está por vir e nele a possibilidade de um espaço público também mais plural, justamente por ser constituída por expressiva diversidade cultural e ambiental. Por mais dramática que seja a presença dos indígenas guaranis no espaço público de Iguape, a exemplo de sua forte presença como vendedores de artesanato por ocasião das festas religiosas e pagãs (seja a Festa do Senhor Bom Jesus de Iguape que reúne cerca de 200 mil pessoas a cada ano no início do mês de agosto, ou o Carnaval de rua de Iguape) é justamente essa presença conflituosa, arisca e ao mesmo tempo passiva que faz com que o simulacro não devore as fissuras por onde o imponderável se expõe como ferida. Talvez esteja justamente nesta presença ainda conflituosa, mas resistente e estrategicamente desejosa de participação, a possibilidade de um outro devir.

Em dezembro de 2009 o conselho consultivo do Iphan aprovou o tombamento do Centro Histórico de Iguape/SP, numa decisão que trouxe novidades importantes para a política de patrimônio no Estado de São Paulo. IPHAN - Instituto do Patrimônio Histórico e Artístico Nacional (Ministério da Cultura - Governo Federal - Brasil).

Para efeitos de comparação acerca de determinados aspectos da formação territorial que envolvem os sítios históricos no cone sul latino-americano, considerou-se ainda a cidade de Colônia do Sacramento e o território missioneiro na fronteira entre Brasil, Paraguai e Argentina.

Colônia do Sacramento é uma cidade uruguaia que está distante cerca de $177 \mathrm{~km}$ de Montevidéu e com população atual em torno de 26.000 habitantes. À margem esquerda-norte (ou oriental) do Rio da Prata nas proximidades de seu estuário que desagua no Oceano Atlântico. Em relação ao sítio histórico urbano, destaca-se o denominado Bairro Histórico, também conhecido como Barrio Sur, Ciudad-Vieja, Antigua Colonia del Sacramento e Ciudad Histórica (FIGUEIRA, 2015: 270) que corresponde ao sítio histórico tombado. Segundo Possamai (2007, p.9):

A Colônia do Sacramento foi fundada na margem esquerda do Rio da Prata em 1680 por D. Manuel Lobo, obedecendo ao plano do príncipe regente D. Pedro de expandir os domínios portugueses na América, a fim de assegurar vantagens territoriais e econômicas à Coroa portuguesa. A ocasião era propícia, pois a decadente Espanha de Carlos II, o último Habsburgo espanhol, não parecia capaz de opor resistência aos 
velhos projetos expansionistas portugueses que visavam dominar o estuário platino e, através dele, assegurar a manutenção do fluxo da prata contrabandeada das minas de Potosí para Lisboa por via dos portos brasileiros.

Desde sua fundação, Colônia do Sacramento conheceu períodos de domínio luso e hispânico, cujas influências na concepção do espaço podem ser observadas no centro histórico híbrido, conjugando lado a lado casas de estilo colonial português e construções tipicamente espanholas. Longe de ser um processo linear, a formação territorial de Colônia do Sacramento envolve profundos embates luso-hispânico por seu domínio territorial, desde a indefinição da delimitação territorial do Tratado de Tordesilhas ao contexto que culmina com o Tratado de Madri (após o qual os territórios envolvidos ainda passariam por redefinições de domínio).

Ao abordar a questão da fronteira territorial das colônias lusa e hispânica observa-se que não somente as porções territoriais de Colônia do Sacramento e das missões jesuíticas guaranis (os Sete Povos das Missões, no atual oeste do Rio Grande do Sul) estiveram diretamente envolvidas nos sucessivos e conturbados tratados. A região de Cananéia-Iguape também é citada no contexto dos questionamentos e entendimento que ambas coroas faziam sobre qual seria a fronteira demarcada pelo Tratado de Tordesilhas (de 7 de julho de 1949), ou seja, ao que de fato correspondia, no terreno, o Meridiano de Tordesilhas traçado a 370 léguas a oeste das Ilhas de Cabo Verde.

Sobre a presença indígena nas terras do atual Uruguai, destaca-se ainda na toponímia contemporânea a referência aos minuanos e aos charruas, cujas denominações recorrentemente são também atribuídas a estabelecimentos comerciais e similares nas terras do sul do Brasil. Mas estes não eram os únicos. Assim como nos demais domínios latinoamericanos, a denominada "banda oriental" da Bacia do Rio da Prata era território de diversos outros grupos indígenas. Museus e arquivos históricos e antropológicos em Montevidéu e Colônia do Sacramento guardam material arqueológico que denota a forte presença destas populações naquele território no período pré-colonial.

Colônia do Sacramento é marcada fundamentalmente pela disputa territorial estando períodos sob domínio espanhol ou português. Contudo, cabe atentar igualmente para os períodos de abandono.

Foi na década de 1960 que tem início o trabalho do Conselho Honorário Executivo de Obras de Preservação e Reconstrução da Antiga Colônia do Sacramento envolvendo escavações arqueológicas, restaurações e reconstruções. Foi no processo de transformação do bairro pobre formado sobre os escombros do que fora a fortaleza Colônia do Sacramento, e a cidade na qual se converteu, que se processou o esvaziamento populacional, culminando com 
sua conformação ao turismo, impulsionado pela situação geográfica defronte ao Porto de Buenos Aires, característica que permite a navegação fluvial de curta duração na travessia entre as duas cidades. Não ao acaso Colônia do Sacramento se tornou uma extensão do lazer dos portenhos, bem como lugar de empreendedorismo de argentinos ligados ao setor turístico.

Assim como Iguape, a cidade de Colônia do Sacramento também passou pelo processo de reconhecimento de seu valor histórico, inserindo-se nos processos de valorização, restauração e tombamento sob as leis do patrimônio. O tombamento da cidade de Colônia do Sacramento como Patrimônio Cultural da Humanidade (UNESCO) ocorreu no ano de 1995. Observou-se que esse processo resultou em expulsão dos antigos moradores, tendo a cidade se transformado numa espécie de cidade museu no contexto das atividades turísticas.

Observou-se também correlações existente entre Colônia do Sacramento e as missões jesuíticas guaranis (que culmina com o Tratado de Madri, na troca territorial das referidas áreas estabelecida entre as coroas ibéricas em suas possessões coloniais). A cidade que conheceu intervalos sob domínio português e sob domínio espanhol esteve diretamente envolvida na definição e redefinição dos limites territoriais de ambas coroas (destaque para o Tratado de Madri, de 1750, dentre outros) até culminar com a definitiva troca com o território onde se encontravam as missões jesuíticas guaranis a leste do Rio Uruguai (também definida como banda oriental do Rio Uruguai), no atual Estado do Rio Grande do Sul.

Desse modo, a pesquisa incorporou essa área de estudo à análise em relação ao longo processo que define e transforma o domínio do público-privado na interface do encontro entre os colonizadores (Espanha e Portugal e as instituições correlatas do período da colonização) e os povos originários desse território, com destaque para os guaranis que, no transcurso do processo de formação territorial se fazem presentes de forma profundamente conflituosa e resistente.

Entre o século XVII e XVIII foram fundadas cerca de trinta missões jesuíticas guaranis (ou reduções) no território denominado como mesopotâmia junto a terras banhadas por rios que integram a Bacia do Prata (com destaque para o Rio Uruguai na divisa atual do Brasil com a Argentina, e do Rio Paraná, na divisa da Argentina com o Paraguai). Os denominados trinta povos existiram nas terras dos atuais territórios do Paraguai, Argentina e Brasil.

Se o modelo geral de construção de uma missão jesuítica era baseado numa estrutura ortogonal de dimensões monumentais, centrado em uma grande praça defronte a um edifício religioso tão imponente quanto era o poder clerical ali representado e exercido, esse território quando se efetiva como posse da coroa portuguesa restará sob a sombra da ruína. Nesse caso, 
a ruína é a forma eleita para ostentar o poderio bélico dos novos detentores do território, às custas das vidas de numerosos indígenas que já haviam perdido seus domínios antes, quando reduzidos nas missões sob comando dos espanhóis.

$\mathrm{O}$ processo como um todo se caracterizou como perverso em relação à concepção indígena acerca do território que originalmente não conhecia fronteiras que o fragmentasse. Tal situação não recai somente sobre os guaranis reduzidos nos séculos XVII e XVIII, mas também para aqueles que a partir da destruição sumária das missões ficaram à deriva entre terras da coroa portuguesa e espanhola, o que na atualidade segue valendo no contexto dos países fronteiriços onde se concentram os povos de língua guarani, com destaque para Paraguai, Brasil e Argentina, e também parte da Bolívia. Fato é que os guaranis, em sua concepção de mundo original, não reconheceriam as fronteiras geopolíticas criadas com base no processo históricos deflagrado no período colonial inscrito numa racionalidade eurocêntrica. Os rios comumente utilizados pela civilização moderna como limites políticoadministrativos (sendo inclusive uma das principais feições naturais do terreno a ser usada como limites das fronteiras internacionais) são concebidos pelos guaranis como meio de integração e articulação territorial, meio de sobrevivência (a pesca e o abastecimento hídrico), de transporte (são excelentes canoeiros) e de unidade identitário de seu território.

Apesar desses sítios se encontrarem em condições de ruínas, a magnitude do plano urbanístico ainda resguarda elementos que permitem identificar seu desenho original, em maior ou menor grau conforme as diversas missões que foram tombadas pelas leis do patrimônio no Brasil, Paraguai e Argentina e se inserem nos circuitos turísticos que integra a dinâmica territorial dessa região de fronteira.

Ainda em relação às questões de conflitos fronteiriços, também o litoral sul paulista foi alvo de discordâncias acerca de qual seria o efetivo traçado da Linha de Tordesilhas (que numa de suas versões apresenta traçado incidente nas imediações de Cananéia-Iguape), cujos tensionamentos correspondem às origens de nossa formação territorial e o concomitante desenvolvimento de relações sociais conflituosas.

Em termos de um estudo comparativo acerca do período recente, é possível perceber os níveis de intervenção e resistência aos impactos da sociabilidade no cotidiano em cada um dos casos considerados. Enquanto Iguape segue reproduzindo em pleno centro histórico, tombado pelas leis do patrimônio, uma vida de vizinhança no tempo lento dessa cidade que polariza o Vale do Ribeira no baixo curso do Rio Ribeira de Iguape, por outro lado a cidade de Colônia do Sacramento cada vez mais se transforma numa espécie de simulacro de cidade, cujos moradores antigos foram sendo (direta ou indiretamente) expulsos pelos circuitos de 
valorização turística com forte participação de estrangeiros, majoritariamente de comerciantes e prestadores de serviços do setor de turismo oriundos de Buenos Aires. A capital argentina está situada do outro lado do Rio da Prata, exatamente defronte à Colônia do Sacramento, cuja travessia fluvial corresponde a um dos negócios rentáveis para o setor turístico. No caso das missões jesuíticas guaranis a consolidação desses sítios arqueológicos sob a proteção das leis do patrimônio oferece enigmática perspectiva de análise sobre o significado das ruínas, do que foram as missões jesuíticas e o que significam hoje no contexto da patrimonialização e do turismo. A magnitude do traçado das respectivas praças no centro de cada missão é algo digno de nota. O espaço da praça no modelo padrão para a construção das missões (sendo que cada uma apresenta particularidades que vão desde as matérias primas usadas para a construção das edificações aos ornamentos artísticos com elementos da flona e fauna local) esteve sob a égide do uso do tempo comandado pela mesma monumentalidade do templo religioso, e evidenciam a magnitude desse capítulo da formação territorial latino-americana.

Com base nessas considerações iniciais, a análise da gênese, transformação e devir do espaço público na América Latina exigiu que outra temporalidade e territorialidade fossem consideradas. A referida gênese já não poderia ser analisada tão somente com base no período colonial, nem se projetaria como um devir refém do modelo eurocêntrico do binômio públicoprivado.

Se a praça - praça maior, praça de armas ou ainda praça da matriz - se consolida como marco referencial em torno da qual se articula o domínio do público no processo de formação das cidades coloniais e do modelo urbanístico das missões jesuíticas guaranis, a gênese da questão antecede tal delimitação no tempo de longa duração. O espaço público definido pelos planos urbanísticos ou pelos costumes, que envolve a apropriação privada do solo e a concomitante conformação do denominado rocio, em nada corresponde à cosmologia indígena sobre o mundo, pois nela não há espaço público em oposição ao privado, posto que não há a noção de propriedade privada. Assim sendo, é necessário um outro percurso de investigação.

Nesse mesmo contexto, pode-se citar como exemplo a compreensão diferencial da delimitação de fronteiras territoriais. Parte-se da aproximação entre as condições ambientais e as práticas culturais estabelecidas pelos povos indígenas - as quais invariavelmente serviram de referenciais para os colonizadores, estando presentes até os dias atuais. Prous (1992, p.107) destaca a pesca em detrimento da caça como um dos atributos que articulam os territórios de ocupação na faixa litorânea e no curso dos rios. Na expressão empregada por Gianesella (2008, p.35): considerar as características da "paisagem das águas" é fator decisivo para 
compreender a configuração do território ocupado, com suas potencialidades e limites a cada período histórico. A existência e/ou proximidade da água são considerados não apenas do ponto de vista do consumo na dieta alimentar, mas também como fator de transporte (rios e orlas marítimas navegáveis), fertilidade do solo, exuberância das matas para obtenção de recursos naturais, dentre outros. Em síntese, a denominada paisagem das águas reúne as condições de acesso (via de transporte) e de permanência no território. Hoje, por outro lado, a ênfase tem sido dada às fronteiras como lugares do encontro ou "zonas de contato" (BURKE, 2005, p.153). Ou seja, para os indígenas os rios são elementos de estruturação dos territórios, situação que permite aos mesmos usufruírem dos benefícios existentes em ambas as margens, posto que os rios articulam, ao invés de separar, as extensões territoriais a serem usufruídas. É nesse território que teve origem a gênese da separação público-privado, com subsequentes transformações correlatas a cada período histórico, contrastando com formas ancestrais de compreender o mundo sem a cisão público-privado. Se o domínio do privado impera cada vez mais, a esfera pública jamais deixou de expressar as contradições e conflitos dessa sociedade desigual.

\section{Uma mirada ameríndia: antes e para além do colonial}

Nos primórdios da colonização estima-se que somente no território que hoje corresponde ao Brasil, existiam cerca de 3 a 5 milhões de indígenas divididos em nações ou tribos com suas respectivas línguas, hábitos e costumes que definiam suas culturas e territórios. Desses, destaca-se para os propósitos deste estudo o tronco Tupi-Guarani, mais especificamente os indígenas guaranis que desde a pré-história até os tempos hodiernos se fazem presentes nas áreas estudadas, seja no litoral sul paulista (região de Iguape-Cananéia), seja na fronteira entre Brasil, Argentina e Paraguai (oeste do Rio Grande do Sul e países vizinhos). Cabe ainda ressaltar que na abordagem sobre a cidade de Colônia do Sacramento, fora do perímetro de presença guarani, encontrou-se referências aos indígenas charruas e minuanos, cuja mão de obra foi empregada na construção (e reconstruções posteriores aos ataques hispânicos) da cidade fortaleza. De acordo com Ramos (2006, p.3),

A partir dos inúmeros estudos realizados sobre a chegada dos Guaranis no atual território gaúcho, a teoria mais provável remete a uma gradual migração de levas de indivíduos da família Tupi-guarani da região amazônica, provavelmente por motivos de adversidades naturais, e que se dispersaram dentro do território do atual Brasil, Argentina e Paraguai. Essa migração resultou na ramificação do tronco Tupi-guarani em duas populações com diferenças linguísticas, econômicas e tecnológicas: a primeira, que ocupou a região do Paranapanema e o litoral leste do Brasil, ou seja, 
de clima tropical, e uma segunda, que é o alvo da nossa atenção, que ocupou o sul do Brasil e regiões correspondentes aos atuais Paraguai e Argentina, ou seja, em um clima mais frio, o que implicou na modificação da cultura agrícola para sua adaptação ao território.

Nessa trajetória que evidencia a presença, supressão e resistência dos guaranis nestes territórios, mesmo diante do longo processo de genocídio e expropriação a que foram submetidos, existem na atualidade cerca de 80 mil indígenas do Tronco Tupi, dentre os quais um total de cerca de 35 mil são guaranis (cerca de 2.500 guaranis, 24.300 guaranis Kaiowá, 3.250 guaranis Mbya e 5 mil guaranis Nhandeva distribuídos nos estados de RS, SC, SP, RJ, ES, MS e PA) do total de cerca de 305 etnias indígenas existentes no território nacional totalizando 817.963 mil indígenas, segundo a Fundação Nacional do Índio - FUNAI:

Desde 1500 até a década de 1970 a população indígena brasileira decresceu acentuadamente e muitos povos foram extintos. O desaparecimento dos povos indígenas passou a ser visto como uma contingência histórica, algo a ser lamentado, porém inevitável. No entanto, este quadro começou a dar sinais de mudança nas últimas décadas do século passado. A partir de 1991, o IBGE incluiu os indígenas no censo demográfico nacional. O contingente de brasileiros que se considerava indígena cresceu $150 \%$ na década de 90 . O ritmo de crescimento foi quase seis vezes maior que o da população em geral. O percentual de indígenas em relação à população total brasileira saltou de $0,2 \%$ em 1991 para $0,4 \%$ em 2000, totalizando 734 mil pessoas. Houve um aumento anual de $10,8 \%$ da população, a maior taxa de crescimento dentre todas as categorias, quando a média total de crescimento foi de 1,6\% (FUNAI, http://www.funai.gov.br, Acessado em 10 março 2018).

A magnitude dessa presença originária, processo de supressão (expropriação e genocídio) e recomposição recente no percentual de participação no conjunto das categorias étnicas do país, são observados na Tabela 1 e Gráfico 1 apresentados a seguir:

Tabela 1 - Dados demográficos da população indígena no Brasil: litoral e interior (1500-2010)

\begin{tabular}{|c|c|c|c|c|}
\hline ano & pop. ind. litoral & pop. ind. interior & total & pop total \\
\hline 1500 & 2.000 .000 & 1.000 .000 & 3.000 .000 & 100,00 \\
\hline 1570 & 200.000 & 1.000 .000 & 1.200 .000 & 95,00 \\
\hline 1650 & 100.000 & 600.000 & 700.000 & 9,00 \\
\hline 1825 & 60.000 & 300.000 & 360.000 & 0,40 \\
\hline 1940 & 20.000 & 180.000 & 200.000 & 0,37 \\
\hline 1950 & 10.000 & 140.000 & 150.000 & 0,10 \\
\hline 1957 & 5.000 & 65.000 & 70.000 & 0,19 \\
\hline 1980 & 10.000 & 200.000 & 210.000 & 0,20 \\
\hline 1995 & 30.000 & 300.000 & 330.000 & 0,20 \\
\hline 2000 & 60.000 & 340.000 & 400.000 & 0,26 \\
\hline 2010 & 272.654 & 545.308 & 817.962 & \\
\hline
\end{tabular}

Fonte: FUNAI. Disponível em: http://www.funai.gov.br Acessado em 10 março 2018 
RELACult - Revista Latino-Americana de Estudos em Cultura e Sociedade

Revista Latinoamericana de Estudios en Cultura y Sociedad | Latin American Journal of Studies in Culture and Society V. 05, ed. especial, mai., 2019, artigo $\mathrm{n}^{\circ}$ 1570 | claec.org/relacult | e-ISSN: 2525-7870

Grafico 1 - Dados demográficos da população indígena no Brasil: litoral e interior (1500-2010)

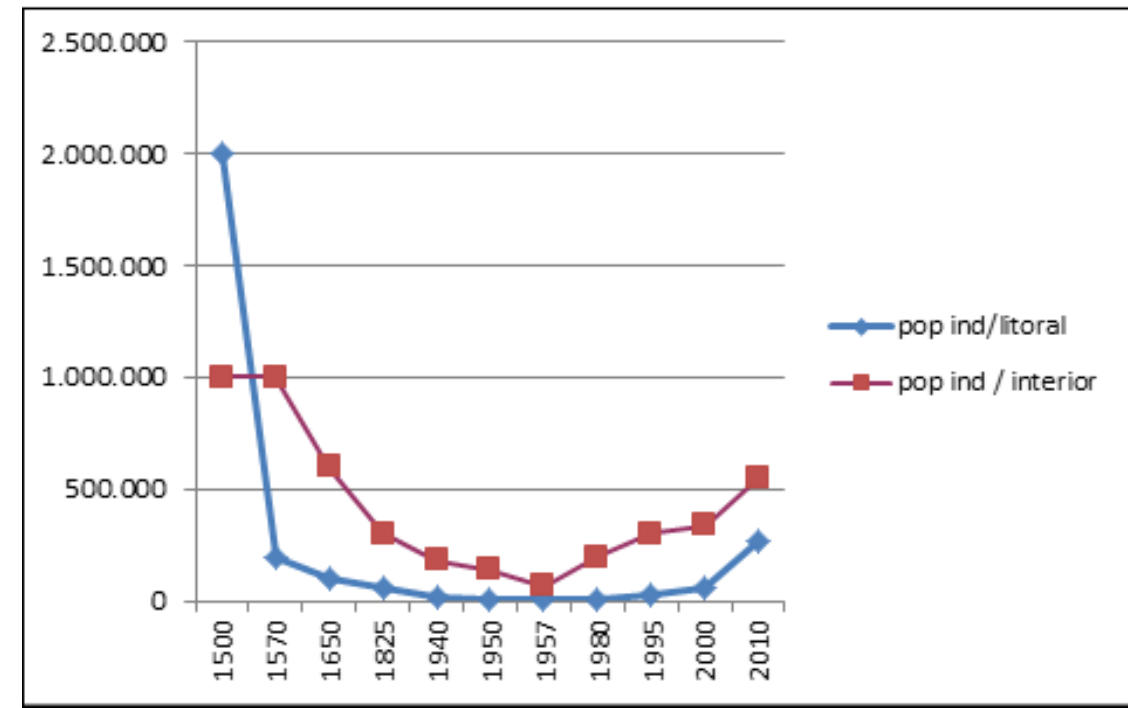

Fonte: FUNAI. Disponível em: http://www.funai.gov.br Acessado em 10 março 2018

No contexto da América Latina, como já indicado, destacou-se os povos guaranis na denominada Bacia do Rio da Prata, ressaltando-se a magnitude do que foi o vasto território da nação guarani. Presente em grande extensão da Bacia do Prata, estende-se do sopé da Cordilheira dos Andes, na Bolívia, até a faixa costeira atlântica, configurando um território transfronteiriço que abriga aldeias e sítios arqueológicos na atualidade (Figura 1).

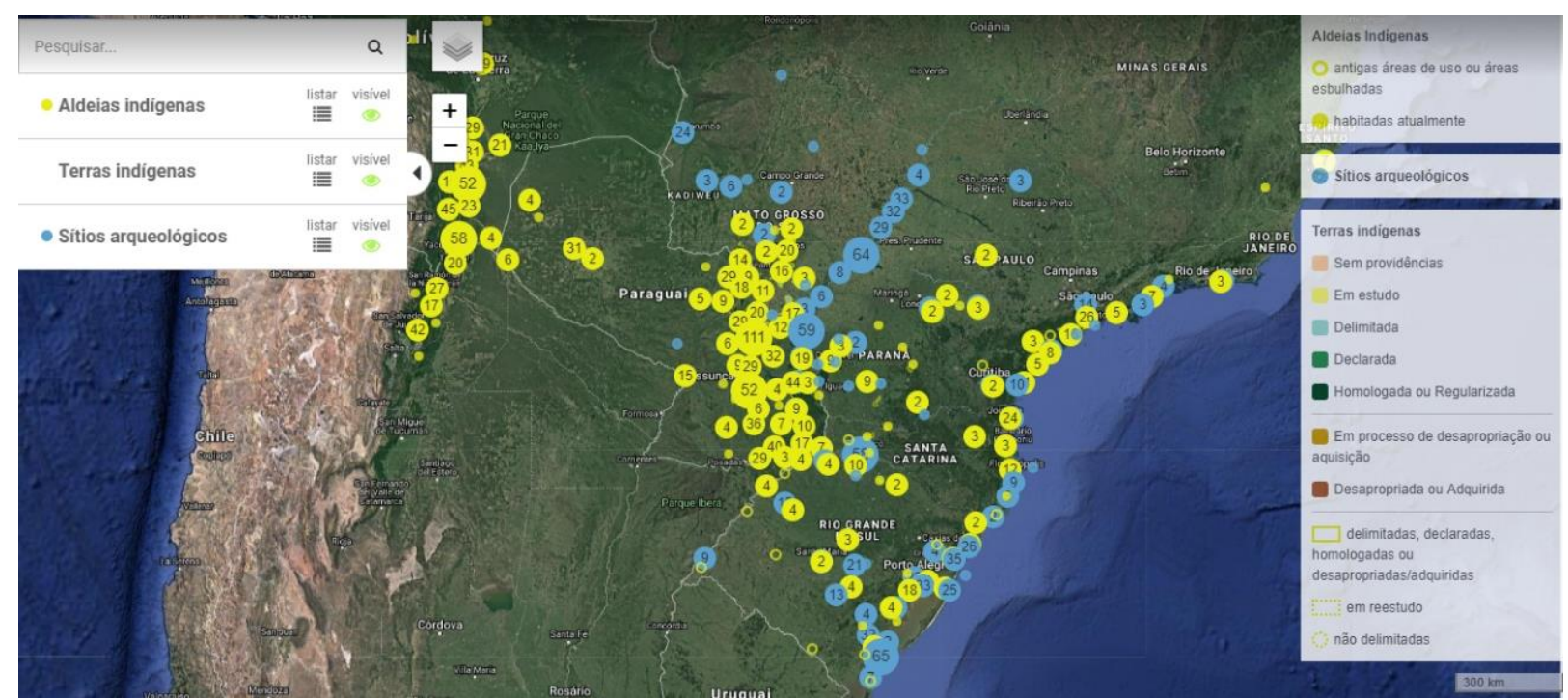

Figura 1 - Aldeias indígenas guaranis e sítios arqueológicos em territórios pré-históricos guaranis (2017).

Fonte: Mapa Guarani Digital. Disponível em: http://guarani.map.as. Acessado em: 10 julho 2018 
Como já mencionado, originalmente o estudo se propôs à análise e compreensão da gênese, transformação e devir do espaço público em centros históricos de cidades criadas no período colonial - Iguape na faixa litorânea atlântica e Colônia do Sacramento na foz do Rio da Prata. Contudo, foi necessário recuar no tempo histórico de longa duração e adentrar a nossa pré-história. Encontrou-se neste procedimento os sítios arqueológicos que abrigam as ruínas das antigas missões jesuíticas guarani, incorporando aspectos da cosmologia guarani na análise do binômio público-privado hegemonicamente concebido segundo a racionalidade eurocêntrica. Tal aproximação demonstrou o quão distante se está de alcançar um entendimento sobre a formação territorial e social da América Latina. Insuficiente é substituir pensadores e teóricos do velho mundo por referenciais de pensadores latino-americanos; esse é um passo importante e necessário; porém é preciso admitir que existe ainda um abismo entre a intencionalidade em se escrever uma geografia autóctone latino-americana e os conhecimentos e visões de mundo dos povos originários desse continente. De acordo com Meliá (1990, p.33),

(...) para o Guarani, e nisto coincidem tanto a arqueologia e a história como observação etnográfica contemporânea, a terra não é nunca um simples meio de produção econômico. Como uma expressão que vem testemunhada desde antigamente e é usual entre os Guarani atuais, sua terra se identifica com o tekoha. Entretanto, a semântica do tekoha corre menos pelo lado da produção econômica que pelo lado do modo de produção de cultura. Teko é, segundo o significado que lhe dá Montoya em seu Tesoro de la lengua guarani (1639: f. 363 s), 'modo de ser, modo de estar, sistema, lei, cultura, norma, comportamento, hábito, condição, costume ...' Pois bem, o tekoha é o lugar onde se dão as condições de possibilidade do modo de ser guarani. A terra, concebida como tekoha é, antes de tudo, um espaço sócio-político. 'O tekoha significa e produz ao mesmo tempo relações econômicas, relações sociais e organização político-religiosa essenciais para a vida guarani... Ainda que pareça um paralogismo, temos que admitir, juntamente com os próprios dirigentes guarani, que sem tekoha não há teko' (Melià 1986: 105). É 'o lugar onde vivemos segundo nossos costumes' (Ibid:104).

Assim, considerou-se a pré-história pregressa ao período denominado como sendo aquele dos “descobrimentos” ou período colonial. Segundo Custódio (2012: p.2),

Antes da Era dos Descobrimentos, o continente americano era ocupado por diferentes culturas e civilizações nativas. Os assentamentos pré-históricos remontam a datações que atingem 12 mil anos antes do presente. Segundo Ribeiro ${ }^{3}$, a América era povoada por ' (...) sociedades de nível tribal, as estruturadas já em estados ruraisartesanais e mesmo os grandes impérios teocráticos de regadio (Inca, Maia e Asteca)'. Pelo Tratado de Tordesilhas firmado em 1494, foram estabelecidos limites para as possessões decorrentes das descobertas das nações ibéricas, inseridas no contexto da expansão do capitalismo mercantil. A ocupação colonial do continente

\footnotetext{
${ }^{3}$ Nota do autor: RIBEIRO, Darcy. A América e a Civilização. Editora Vozes Ltda. Petrópolis, RJ. 1977. p.41.
} 
americano deu-se a partir e ao longo do litoral Atlântico pelos portugueses, e a partir do Caribe, de noroeste para o sudoeste, ao longo da costa pacífica, pelos espanhóis. Com a chegada dos conquistadores, iniciou-se o processo de transformação e extinção de povos, civilizações e culturas estabelecidas tradicionalmente em todo o continente.

Recorreu-se aos estudos acerca da pré-história que antecede o período colonial. Assim sendo, além do diálogo com historiadores, a pesquisa considerou contribuições da Arqueologia e da Antropologia. A este respeito, vale ressaltar que não apenas as ruínas das missões jesuíticas guaranis se apresentam como área de interesse dos referidos campos do conhecimento. Há sítios associados à ocupação pretérita indígena no perímetro urbano de Iguape (sobretudo em direção à Icapara, lugarejo reconhecido como local de fundação de Iguape, e a Barra da Juréia, contíguos à um território indígena recentemente demarcado), e nas imediações de Colônia do Sacramento, cujo centro histórico tombado segue sendo alvo de estudos arqueológicos.

\section{Duas cidades coloniais, um território de fronteira e uma síntese}

Ao propor estudo sobre um universo de análise inserido no processo de formação territorial da América Latina, o trânsito entre países vizinhos leva a uma aproximação com outras culturas, outras perspectivas geopolíticas e culturais, e nisso tudo o encontro com o idioma espanhol. Num primeiro momento, a aproximação com esse idioma, da mesma matriz latina do português, indica aproximação em relação aos países hermanos. Contudo, nessa aproximação linguística (entre a língua portuguesa e a língua espanhola) ainda reside um abismo em relação a outras narrativas, como as ameríndias, que pudessem revelar outras formas de ver esse mesmo território de análise e que traduzisse uma complexidade mais profunda da formação territorial latino-americana.

Segundo informação da FUNAI (com base no censo do IBGE de 2010) foram registradas no país 274 línguas indígenas, sendo que 17,5\% da população indígena não fala o idioma português. Se a língua é um dos atributos identitários mais fortes e irredutíveis da constituição do sujeito, e prova inconteste da resistência e perpetuação de um povo, trata-se de um universo a ser compreendido no contexto latino-americano. A complexidade dessa formação social e territorial está nos fundamentos das contradições e conflitos presentes no processo de gênese, formação e transformação do espaço público na América Latina. 
Sob uma perspectiva ocidental-eurocêntrica, a gênese do processo de formação territorial da América Latina, inserido no período colonial de expansão ultramarina das coroas ibéricas, situa-se no contexto mais amplo da denominada Idade Moderna, com avanços nos campos do conhecimento (a exemplo da construção naval), impulsionado pelo horizonte dos novos territórios incorporados ao mundo conhecido de então. Contudo, há uma sistemática omissão, ou silenciamento, sobre os povos e nações ancestrais destas terras que, de acordo com Ribeiro (1995: p.31) somavam cerca de 1 milhão de indígenas no período identificado como "dos descobrimentos". Na apresentação do tema da gênese dos sítios históricos urbanos sob uma perspectiva latino-americana, há que se considerar que:

\begin{abstract}
A história das sociedades europeias ("nosso" tipo de sociedade), contrapondo-se às sociedades dos outros (o tipo de sociedade "deles"), foi sempre realçada por uma ênfase na história "escrita". A distinção entre sociedades com escritas e aquelas sem escrita exerceu um papel importante nas ciências humanas, e se agregava a outras dicotomias como: mito/história, barbárie/civilização, primitivo/avançado. Essas dicotomias enquadraram nossa compreensão da evolução social e da história da humanidade desde, ao menos, o século XVIII, e seu poder é tamanho que elas continuam a dominar as tradições a-histórica, funcionalista e estruturalista do início até a metade do século XX (FUNARI, 2007, p.50)
\end{abstract}

A predominância do registro histórico baseado na escrita, subtrai das narrativas hegemonicamente de matriz europeia um cabedal de fontes não escritas, de tradição oral, alicerçado num diversificado e distinto modo de interpretação do mundo, que potencialmente revelariam outras compreensões sobre a gênese do processo de formação territorial e social, além dos vestígios arqueológicos concretos, tais como ruínas e objetos dos sítios arqueológicos. De acordo com Gianesella (2008, p.22):

\begin{abstract}
Recentemente, alguns trabalhos procuram resgatar a real importância das populações nativas no processo histórico brasileiro. São Interpretações críticas das posturas historiográficas que quase relegaram a estas sociedades o papel de coadjuvantes, quando não, omitiram-nas. Não faltaram razões a esta parcialidade, sedimentada ao sabor dos dominadores: ou considerava a inferioridade racial e defasagem evolutiva, ou enalteciam o bandeirismo ou, ainda, entre outras razões, privilegiavam as fundamentações econômicas do colonialismo de matriz europeia e produção periférica, com os espaços e a sociedade respondendo a este recorte conjuntural.
\end{abstract}

Evidente que a gênese do espaço público nestes termos traz a marca da incompletude e da sua própria negação, uma vez que desde sempre a pluralidade e a diversidade foram destruídas sob a racionalidade eurocêntrica que definiu muito precocemente uma separação fundante: o "nós" (brancos, letrados, cristãos, civilizados...) - supostamente aptos a usufruir 
do espaço público e da política - e os "outros" (os indígenas, também os negros, suas descendências e os segmentos sociais empobrecidos).

Azevedo (1957) elenca uma tipologia de formas embrionárias ao surgimento dos núcleos urbanos e observa que ao contrário dos aldeamentos (relacionados com missões religiosas), as aldeias não devem ser consideradas embriões para uma análise evolutiva das formas urbanas. Há concordância de entendimento a respeito, sobretudo em relação ao binômio público-privado, uma vez que para a cosmologia indígena (e no caso abordado, a guarani) não há correspondência para a noção de propriedade privada. Ainda sobre esse tema, e de acordo com Custódio (2012, p.4-5),

\begin{abstract}
O trabalho e as decisões são comunitários. A economia é baseada na reciprocidade e inexiste o conceito de propriedade privada, apesar de haver áreas de cultivo individualizadas, estabelecidas pelo consenso do grupo. (...). O Guarani não gosta de trabalhar só, nem de ser mandado. Prefere convidar e ser convidado. Trabalha em butiró (mutirão), em chiquitano, minga. (...) A grande maloca guarani que tradicionalmente podia abrigar uma família extensa - integrada por pais, mães, tios, primos e todos os parentes, com quase uma centena de pessoas - foi sendo transformada ao longo do tempo, passando por unidades habitacionais menores que abrigavam três ou quatro famílias cada uma. Eram casas de palha, com esteios de madeira, onde eram penduradas as redes de dormir. Esta relação casa/oka era fundamental na vida social e religiosa do grupo. O tekuá é o conceito básico que expressa a unidade sócio-política Guarani. Representa uma maloca ou rancho e geralmente está identificada com a família extensa. É o termo utilizado para expressar o lugar onde o Guarani é o produto e o produtor de sua cultura.
\end{abstract}

Há o espaço da privacidade (as denominadas malocas onde se abrigaram em grupos familiares e compadrios) mas não a propriedade privada tal como compreendido na perspectiva moderna, contemporânea e eurocêntrica no contexto do sistema econômica capitalista. A respeito, contribuições sobre o tema do espaço público desenvolvidas, por exemplo, pela Escola de Frankfurt, dentre outras situadas de fora e de longe da realidade aqui analisada, não parecem oferecer um caminho metodológico e analítico que abarque a diversidade e especificidades a serem consideradas com base no universo indígena latinoamericano. Por outro lado, além dos aldeamentos indígenas, Azevedo (1957) cita como "vetores embrionários" os arraiais, fortificações e postos militares, patrimônios religiosos, pousos de viajantes e estações ferroviárias (GIANESELLA, 2008, p.25). Os casos analisados se inserem no conjunto dessa tipologia, envolvendo a questão da fortificação e do patrimônio religioso, e em todos os casos a função econômica-comercial predomina como fundamento de suas origens. Seja no traçado do sítio, seja no desenvolvimento das relações sociais, observase a presença do conflito e da definição acerca do que é o espaço público e o espaço privado. 
Contudo, considerações sobre a presença indígena é praticamente inexistente em amplo espectro da literatura sobre o tema das origens dos núcleos urbanos e do espaço público.

Mesmo quando o fator religioso não é preponderante (no caso de Colônia do Sacramento) as edificações com função religiosa e a organização espacial do entorno (praças, largos e arruamentos) estão marcadamente ordenados por este fator, assim como o ritmo das relações sociais. Isto é demonstrado, por exemplo, na obra "Nosso chão: do sagrado ao profano", de Murilo Marx (2003), cuja contribuição se estende à análise da metamorfose do sagrado ao profano ou, em outros termos, o processo de laicização social.

Gianesella (2008), assim como Ribeiro (1995), Prous (2006), Funari (2007), Scatamacchia; Uchôa (1993) dentre outros também ressaltam a importância dos textos dos cronistas do período colonial (sobretudo nos séculos XVI e XVII) que trazem elementos ausentes nos documentos oficiais dos colonizadores, cuja perspectiva analítica omitiu, ou distorceu, em seus registros a participação dos povos originários.

Contudo, há acumulada discussão sobre as origens dos povos ancestrais nestes territórios, em duas frentes de expansão (uma frente Atlântica e outra interiorana seguindo pela Bacia do Prata) que definem um território denso em conflitos, seja entre os povos indígenas (com destaque para os tupinambás e os guaranis) seja entre as coroas ibérica e hispânica nos primórdios da definição dos limites territoriais coloniais.

Ressalta-se que essas disputas territoriais entre as coroas ibéricas articulam num mesmo contexto as áreas de estudo: Iguape, Colônia do Sacramento e o território missioneiro. A seguir, numa citação da obra de Gianesella (2008), observa-se o conflito envolvendo a indefinição da fronteira colonial na região de Cananéia-Iguape:

Uma intrigante conjunção de fatores encadeia-se nessa região. O mesmo destino da discutível 'zona de fronteira' na região será superposto pela partilha do novo mundo entre portugueses e espanhóis, jurisdicionado no Tratado de Tordesilhas. Cananéia torna-se 'razoavelmente' aceita entre os ibéricos como marco sul da linha imaginária que dividia o continente. Talvez a presença portuguesa pioneira tenha assegurado isso, valendo a 'pressuposta' intenção de Gonçalo Coelho no desembarque de Cosme Fernandez nestas paragens. Veremos que no episódio da 'Guerra de Iguape' essa posse portuguesa foi contestada (...) (GIANESELLA, 2008, p.123-124)

Além da correlação existente entre Colônia do Sacramento e as missões jesuíticas guaranis (que culmina com o Tratado de Madri na troca territorial estabelecida entre as coroas hispânicas em suas possessões coloniais) o litoral sul paulista também se apresenta como lócus dessas disputas, cujos tensionamentos correspondem às origens de nossa formação 
territorial e nela o desenvolvimento das relações sociais, do comércio regido pelo pacto colonial ao contrabando prematuramente praticado nessas terras.

Acerca da aproximação entre as condições ambientais e as práticas culturais estabelecidas pelos povos originários - as quais invariavelmente seguiram sendo referenciais para os colonizadores, estando presentes até os dias atuais - Prous (1992, p.107) destaca a pesca em detrimento da caça. Gianesella (2008) também enfatiza esse aspecto:

O conjunto mais favorável à captação alimentar é o das enseadas, baías, e lagunas, contato com o ambiente marinho e terrestre, entre a água salgada e doce. (...) A penetração do ambiente marítimo dentro do continente torna vizinhos o campo, a mata e o mar, concentrando, num raio mínimo, recursos que, em geral, se acham separados. (...) Portanto, a ocupação corresponde à rede hidrográfica principal, como se fosse uma teia de aranha entre os fios da qual subsistiram ilhotas abandonadas aos tradicionais habitantes da região que sobreviveram nos relevos, que os Tupiguaranis canoeiros não cobiçavam e onde evitavam aventurar-se (...) (PROUS, 1992, p.202;373 Apud GIANESELLA, 2008, p.35-36).

Com base nestas passagens das obras citadas, conjugadas com demais fontes e observações em campo, pode-se afirmar que o elemento água é imprescindível na definição dos sítios ocupados. Importante a contribuição de Gianesella (2008, p.48-49) para o qual,

\footnotetext{
Qualquer tentativa, inclusive a nossa, de representar geograficamente as áreas de ocupação das sociedades indígenas da frente atlântica do sudeste brasileiro no distante século XVI, estará suscetível a imprecisões. Nem tanto pela escassez de fontes documentais (etno-históricas), ou de investigações arqueológicas (satisfatório em alguns setores, todavia, aquém dos anseios da ciência), mas pela natureza dinâmica das populações envolvidas especialmente naquele recorte de tempo. (...) Os nossos referenciais geopolíticos e jurídicos sobre a posse da terra sublimam o significado ambiental das bacias hidrográficas, só recentemente objeto de posturas protetivas enquanto ecossistemas específicos. As nossas sociedades pré-coloniais incorporavam há séculos esta sabedoria, como tantas outras. Os sítios da subtradição Guarani, por exemplo, investigados pela arqueologia, evidenciam escolhas no contexto integral da via fluvial. Decerto não compreenderiam que pescassem ou instalassem aldeias em apenas uma das margens...
}

Se, por um lado, a denominada "paisagem das águas" (GIANESSELA, 2008) é substrato para os sítios históricos analisados, não se pode desconsiderar as modalidades de articulação terrestre que estão na base da definição dos antigos (e novos) caminhos que propiciaram a integração do vasto território latino-americano. É neste contexto que emerge a importância dos registros deixados por caminhos emblemáticos como o Peabiru que, sendo originariamente um percurso ancestral indígena foi tomado como base para os avanços coloniais. A exemplo da magnitude da Bacia do Prata (e todos os significados a ela associados 
no processo de expansão colonial), as trilhas e caminhos terrestres indígenas também precedem o avanço dos colonizadores, de jesuítas a bandeirantes. Observa-se que esses caminhos estão predominantemente numa posição perpendicular à orientação norte-sul da rede hidrográfica, fazendo a interligação litoral-interior:

\begin{abstract}
Krone encontrou em Cananéia um machado de cobre cuja a de análise feita em laboratórios austríacos demonstrou a origem andina da matéria-prima. Mais recentemente arqueólogos encontrarem vestígios de uma ramificação do mais famoso desses caminhos, o Peabiru dos cronistas, que ia justamente de Cananéia até o local onde fora fundada a cidade de Assunção. A via principal subia o Vale do Ribeira até a nascente, cruzando depois o Paraná, onde atravessava as águas do Tibagi e do Ivaí, descendo depois o Vale do Piquiri até o Paraná, saindo então do território brasileiro. (PROUS, 1992, p.374 Apud GIANESSELA, 2008, p.38).
\end{abstract}

Na abordagem sobre cada uma das áreas analisadas é possível discorrer sobre o conjunto de espaços públicos nelas existentes, cujas origens foram definidas por planos urbanísticos (a vila colonial de Iguape, a cidade fortaleza de Colônia do Sacramento e o modelo urbanístico das missões jesuíticas). Em todas elas a praça se apresenta e se consolida como o espaço público por excelência. A novidade não está exatamente nesse fato, já bastante conhecido dentre as modalidades de espaços públicos. A novidade está na resistência que atravessa o tempo histórico de longa duração, das frestas que dão visibilidade a conflitos profundos e que se reproduzem hoje, como a presença dos indígenas com suas línguas, costumes, com seus artesanatos nas praças de Iguape e em alguns setores dos sítios arqueológicos das missões, ou ainda a resistência de moradores antigos em Colônia do Sacramento, em detrimento do avanço de sua transformação numa tipologia de cidade museu.

Duas cidades, um território de fronteira e uma síntese contraditória. O próprio binômio público-privado se apresenta muito mais complexo e conflituoso quando considerado sob a perspectiva indígena (com destaque para a cosmologia guarani) em contraponto à concepção eurocêntrica dos termos. A inexistência originária da separação público-privado na concepção do mundo guarani oferece esse desafio às concepções consolidadas sobre o tema que, majoritariamente, desconsideram essa questão. A perspectiva indígena, que atravessa o tempo histórico de longa duração, é um terceiro termo interposto ao par de opostos público-privado. Essa tríade colabora para uma compreensão mais complexa sobre a essência do espaço público latino-americano. 


\section{Conclusões}

No tempo histórico de longa duração o espaço público é atravessado por cerceamentos, conflitos e formas de apropriação de diversas ordens. Resulta que na contemporaneidade o espaço público revela acúmulos de conflitos, resistências e potencialidade de uma outra sociabilidade. Sua natureza intrínseca enquanto lócus do encontro e de expressão das práticas público-políticas permitem desvelar os fundamentos da sociedade que o tece. Uma perspectiva de análise no tempo de longa duração, e a abordagem interdisciplinar, colaboram para essa compreensão. Sobretudo quando a perspectiva eurocêntrica de análise do processo de formação territorial, e sobre a gênese e transformação do espaço público, é cotejada pelas possibilidades de outras formas de compreensão, a exemplo daquelas oriundas dos povos indígenas latino-americanos.

Assim sendo, o espaço público segue expressando, às vezes de forma explosiva (como nas festas populares, do sagrado ao profano), às vezes de forma agonizante (no que resta nas frestas do espontâneo, no simulacro que o toma para os negócios turísticos) sua essência.

\section{Referências}

AZEVEDO, A. Vilas e cidades do Brasil colonial. São Paulo: USP/FFLCH. Boletim n.208, Geografia, n.11, 1956.

BURGOS, R. Direito à cidade: utopia possível a partir do uso e apropriação dos espaços públicos urbanos. In: COLOQUIO INTERNACIONAL DE GEOCRÍTICA. LAS UTOPÍAS Y LA CONSTRUCCIÓN DE LA SOCIEDAD DEL FUTURO, 14., 2016, Barcelona. Anais... Barcelona, 2016.

BURKER, P. O que é história cultural? Trad. Sérgio Góes de Paula. Rio de Janeiro: Jorge Zahar, 2005. $191 \mathrm{p}$.

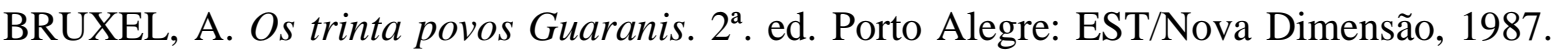
$166 \mathrm{p}$.

DIEGUES, A.C. O Vale do Ribeira e Litoral de São Paulo: meio-ambiente, história e população. CENPEC, 2007.

EISENBERG, J. As missões jesuíticas e o pensamento político moderno: Encontros culturais, aventuras teóricas. Belo Horizonte: Editora UFMG, 2000. 264 p.

FIGUEIRA, M. C. Patrimônio Cultural da Humanidade e Mercado Turístico: o Bairro Histórico de Colônia do Sacramento, Uruguai. Patrimônio e Memória, São Paulo, v. 11, n. 1, p. 262-282, jan./jun. 2015. 
FORTES, R. Iguape... nossa história. Vol. 1. Iguape: Gráfica Soset, 2000. 304 p.

FUNARI, P.P. Teoria e a arqueologia histórica: a América Latina e o mundo. In: Vestígios Revista Latino-Americana de Arqueologia Histórica. Belo Horizonte, v.1, n.1, p.49-56, dez., 2007.

FUNDAÇÃO NACIONAL DO INDIO. Disponível em: http://www.funai.gov.br Acessado em 10 março 2018

GIANESELLA, R. R. Paisagens no tempo: vilas litorâneas. 2008. 191 f. Dissertação (Mestrado - Área de Concentração: História e Fundamentos da Arquitetura e Urbanismo) Faculdade de Arquitetura e Urbanismo, Universidade de São Paulo, São Paulo. 2008.

LEFEBVRE, H. O direito à cidade. São Paulo: Moraes, 1991.

MARX, M. Nosso chão: do sagrado ao profano. São Paulo: EDUSP, 2003. 219 p.

NASCIMENTO, F. B. do; SCIFONI, S. O tombamento de Iguape como patrimônio nacional: novas práticas e políticas de patrimônio nacional. PARC Pesquisa em Arquitetura e Construção, Campinas, v. 6, n. 1, p. 26-38, jan./mar., 2015.

POSSAMAI, P. C. O cotidiano da guerra: a vida na Colônia de Sacramento (1715-1735). 352 f. Tese (Doutorado - História) - Faculdade de Filosofia, Ciências e Letras, Universidade de São Paulo, 2001.

POSSAMAI, P. C. O Rio da Prata como fronteira sul do Brasil. In: GARCIA, D.S. da C.; MICELI, P. C. (Org). História e Fronteira. Cáceres: UNEMAT Editora, 2014. p. 57-68

POSSAMAI, P. C. A Colônia do Sacramento: uma praça de guerra do Império Colonial Português. In: História em Revista, Pelotas, v. 13, p. 09-28, dez., 2007

PROUS, A. O Brasil antes dos brasileiros: a pré-história de nosso país. $2^{\text {a }}$ ed. Rio de Janeiro: Zahar, 2007. 102 p.

RIBEIRO, D. O povo brasileiro. São Paulo: Companhia das Letras, 1995. 453 p.

SCATAMACCHIA, M.C.C. e UCHÔA, D.P. O contato euro-indígena visto através de sítios arqueológicos do Estado de São Paulo. In: Revista de Antropologia. São Paulo, n.7, p.153$173,1993$.

YOUNG, E.G. Subsídios para a história de Iguape. In: Revista do IHGSP. São Paulo: Tipografia do Diário Oficial, vol.II, p.286-375, 1908. 